\title{
Isolated Soft Switching Current Fed Series LC Resonant DC-DC Convertor for Electrical Vehicle Application
}

\author{
Anand Sharma $^{a}$, Dr. Vinesh Agarwal ${ }^{\text {b }}$ \\ ${ }^{a}$ Research Scholar Department of Electrical Engineering, Sangam University, Bhilwara, Rajasthan \\ ${ }^{\mathrm{b}}$ Associate Professor, Department of Electrical Engineering, Sangam University, Bhilwara, Rajasthan \\ a'Email: eeanandsharma@gmail.com, ${ }^{\mathrm{b}}$ Email: vinygoyal@gmail.com
}

Article History: Received: 10 November 2020; Revised 12 January 2021 Accepted: 27 January 2021; Published online: 5 April 2021

\begin{abstract}
The current fed series resonant converter for electrical vehicle application is offered in this paper. The converter is able to achieve ZVS for primary side semiconductor switches. In the overlap time of voltage and current at zero crossing series resonant tank circuit is gives short interval of resonant pulse. This resonant pulse provide natural voltage decrease for semiconductor switches and voltage pulse is zero earlier compare to current across switches and ZVS achieve for semiconductor switches. All devices turn off softly so dependency on snubber is decreased to clamp the voltage across the switches. Presented converter reduce the circulating current so switching losses is decreased and converter efficiency will improvise. The proposed converter is simulated in MATLAB Simulink environment to investigate and analyses the proposed converter.
\end{abstract}

Keywords: electrical vehicles, State of charge, DC-DC Convertor, Buck-Boost Convertor, Zero Voltage Switching

\section{Introduction}

These days' solution for the environmental pollution and $\mathrm{CO}_{2}$ emission through the conventional energy resources are major problem for the world is providing by the EV's and HEV's. Now day's scientists, government and industries pay more attention on renewable energy resources and electrical vehicles to reduce $\mathrm{CO}_{2}$ emission and reduce the uses of fossil fuels uses [1]. Generally the battery uses in electrical vehicle are more half kW rating and isolated $\mathrm{dc} / \mathrm{dc}$ convertor for power conversion is used [2].

Conventional dc-dc converters realize the main necessity of assimilating alternative energy sources into dc microgrids. The adaptable power supply voltage makes it difficult for semiconductor devices to switch in a considerable operating range, which greatly reduces the converter efficiency. If we can limits convertor process at high frequency subsequent

In larger magnetics and immense system. The main key task is to be attain soft-switching for semiconductor devices when source voltage and load has wide dissimilarity. While achieving the soft switching has highly reliable, and volume, and cost is low of the converter [3].

In the works, assessment of soft switched voltage served convertor and current served convertor is presented. The current fed convertor has various advantages such as small input current wave and inherent short circuit current protection, high voltage gain, higher efficiency, wide soft switching range these advantages makes current-fed topology more popular for HV gain and low voltage high current use. With the current fed converter high voltage spikes through the semiconductor devices through turn-off is the main task with the current-fed converter, inactive sunbber take stress-free solution to defeat the device turn-off voltage point but with this convertor efficiency is compromise. Instead of use active clamping achieves and passive sunbber, ZVS of the semiconductor switches and result is enhanced effectiveness but its ads to the peak currents, and reduce boost capacity [4].

Various techniques and innovative topologies permitting soft-switching and removing the essential of outmoded snubber circuit has been stated in literature. The idea of sunbberless natural commutation and voltage clamping of semiconductor switches by applying secondary regulation in many current fed methods. Current operated resonant converter utilizing high frequency transformer and resonant tank and circuit parasitic to achieve soft switching for switches [5].

This paper investigate the zero voltage switching for front end switches for Converter. The battery side converter designated as a current fed full bridge boost converter to attain double voltage gain from primary to secondary transformer. Converter action and regulator is explained in section II. Detailed steady state 
investigation is explained in section III. Design steps exist presented in section IV. Simulation effects are explain in section $\mathrm{V}$ to validate the investigation. Conclusion are strained in section VI.

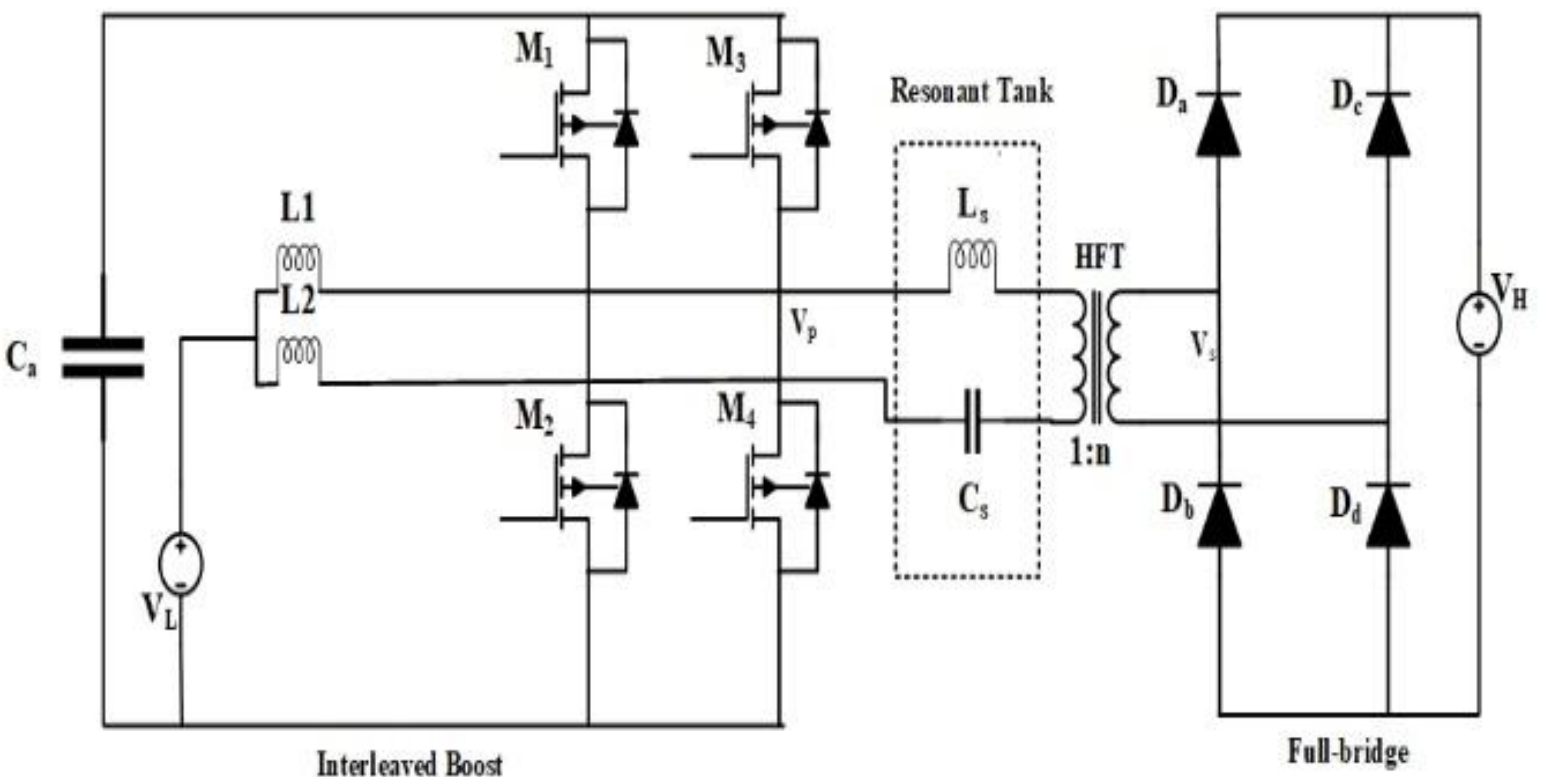

Fig. 1. Offered Isolated Soft Switching Current Fed Series LC Resonant DC-DC Converter

\section{Proposed Convertor Technique And Operation Principles}

\section{A. Proposed converter}

The recommended series resonant converter is presented in fig. 1, presented converter has capability to offer high voltage output due to its interleaved boost connected to the primary of the HF transformer, and secondary side of the HF transformer connected with diode bridge rectifier. The resonant tank circuit is used to provide smooth sine wave at both secondary and primary verges of the high frequency transformer, which allows low conduction losses of switching devices. A resonant indictor $\mathrm{L}_{\mathrm{s}}$ and capacitor $\mathrm{C}_{\mathrm{s}}$ used as to realize ZVS for primary side of the switches. If the voltages of $\mathrm{V}_{\mathrm{H}}$ and $\mathrm{V}_{\mathrm{L}}$ are constant by DC source, the current be able to be controlled by current control loop, then voltages of $\mathrm{V}_{\mathrm{L}}$ or $\mathrm{V}_{\mathrm{H}}$ can be straight delimited by voltage control loop [6].

\section{B. Modulation and Operating Principles}

An easy PWM control technique is adopt to control the series resonant DC-DC converter. The SF of the convertor is static at the series resonant tank. The semiconductor switches are connected in the similar pare are operated opposite The 2 switching leg on the primary side function in an interleaving mode. The subsequent examination will designate that the voltage gain charterstics of the planned series resonant dc/dc is very like to the PWM converters, those voltage gain also controlled through the duty cycle of the switches, thus the moved power and the way of power movement can be controlled simply through modest PWM regulator.

\section{Stady State Analysis}

This part of the article describe about the steady state process and examination of the series resonant $\mathrm{dc} / \mathrm{dc}$ current fed converter. Designed for abridging the convertor investigation, the subsequent assumption are complete

a) A higher significance of the boost inductor is selected to transfer a inflexible dc current.

b) Completely semiconductor switches are idyllic and loss free.

c) The output filter capacitor value is sufficient to provide the continuous output voltage.

d) Capacitor $\mathrm{C}_{\mathrm{s}}$ and inductor $\mathrm{L}_{\mathrm{s}}$ of the high frequency transformer constitute for resonant tank parameter. 


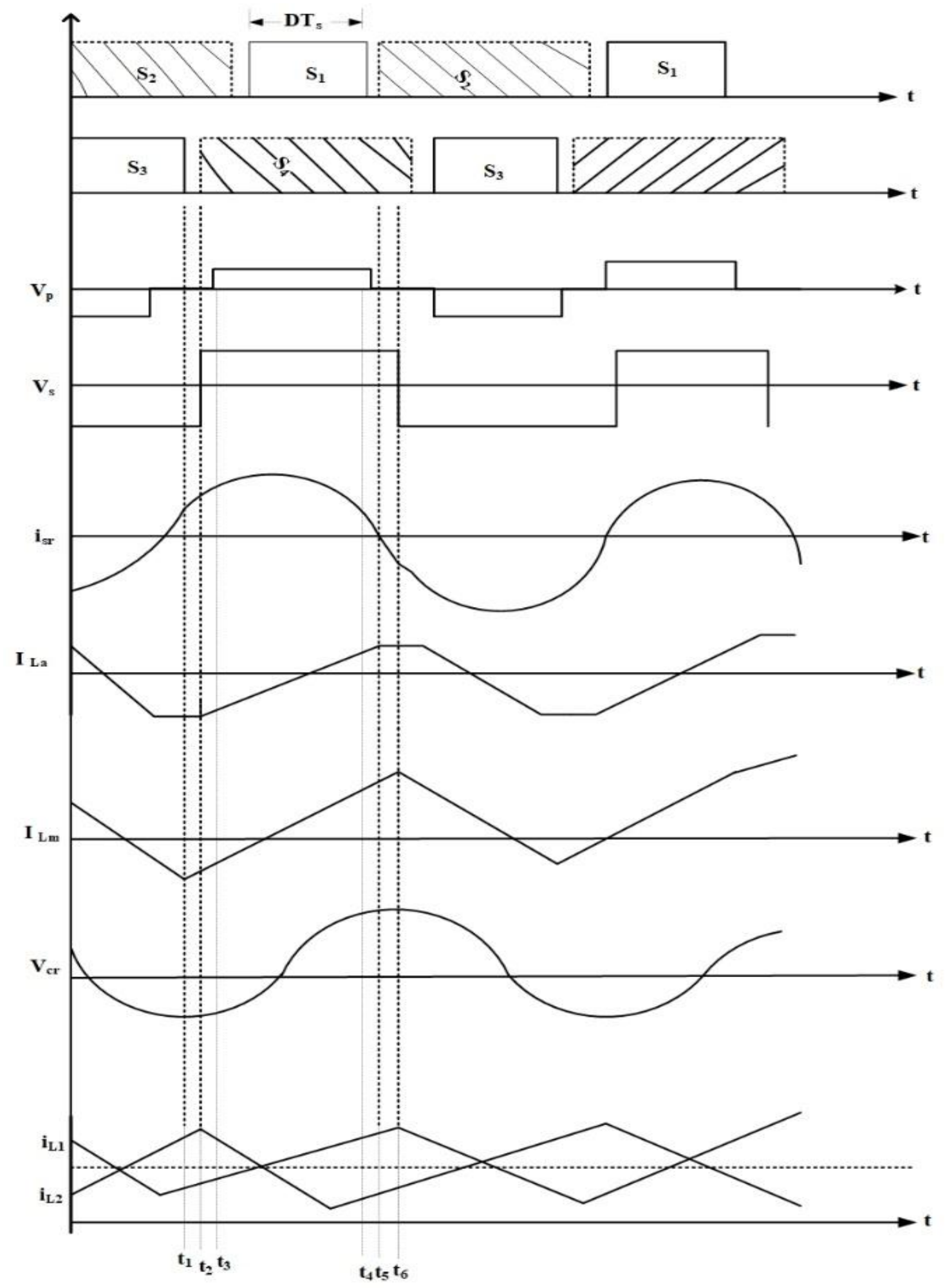

Fig.2 Series resonant converter steady state waveform on forward mode of conduction

Mode $I\left[t_{0}-t_{1}\right.$ ] [Fig. 3(a)] earlier $t_{0}, M_{2}$ and $M_{4}$ are closed to 0 at the center voltage $V_{p}$ of the primary side bridge, while the center voltage $V_{s}$ of the secondary side is $-V_{H}$ at $t_{0}$, and then the diodes $D_{a}, D_{d}$ are converted to $\mathrm{V}_{\mathrm{H}}$.

Mode II $\left[\mathrm{t}_{1}-\mathrm{t}_{2}\right][$ Fig $3(\mathrm{~b})]$ at $\mathrm{t}_{1}$ the diode $\mathrm{D}_{\mathrm{a}}$ and $\mathrm{D}_{\mathrm{d}}$ in forward conduction. 


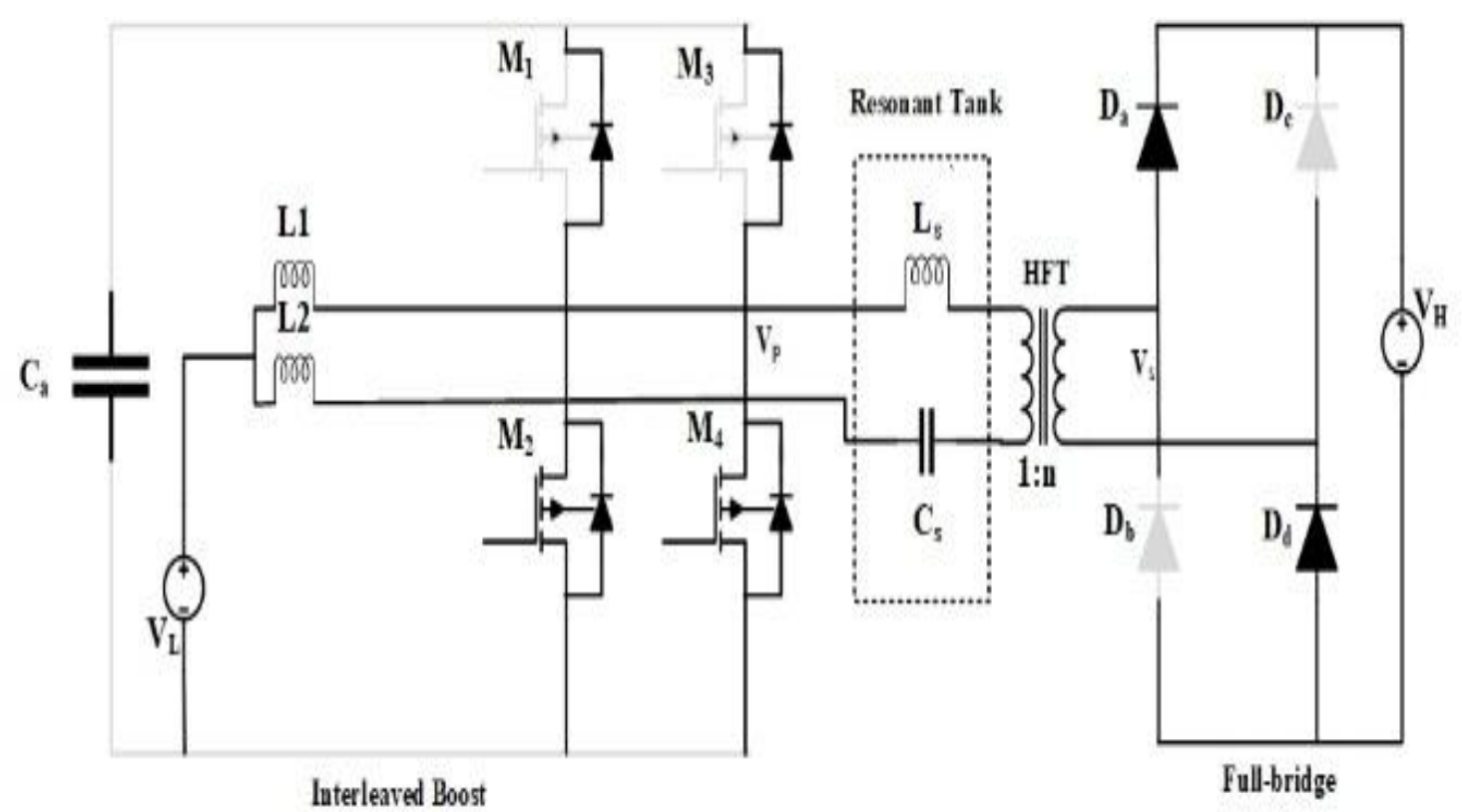

(a)

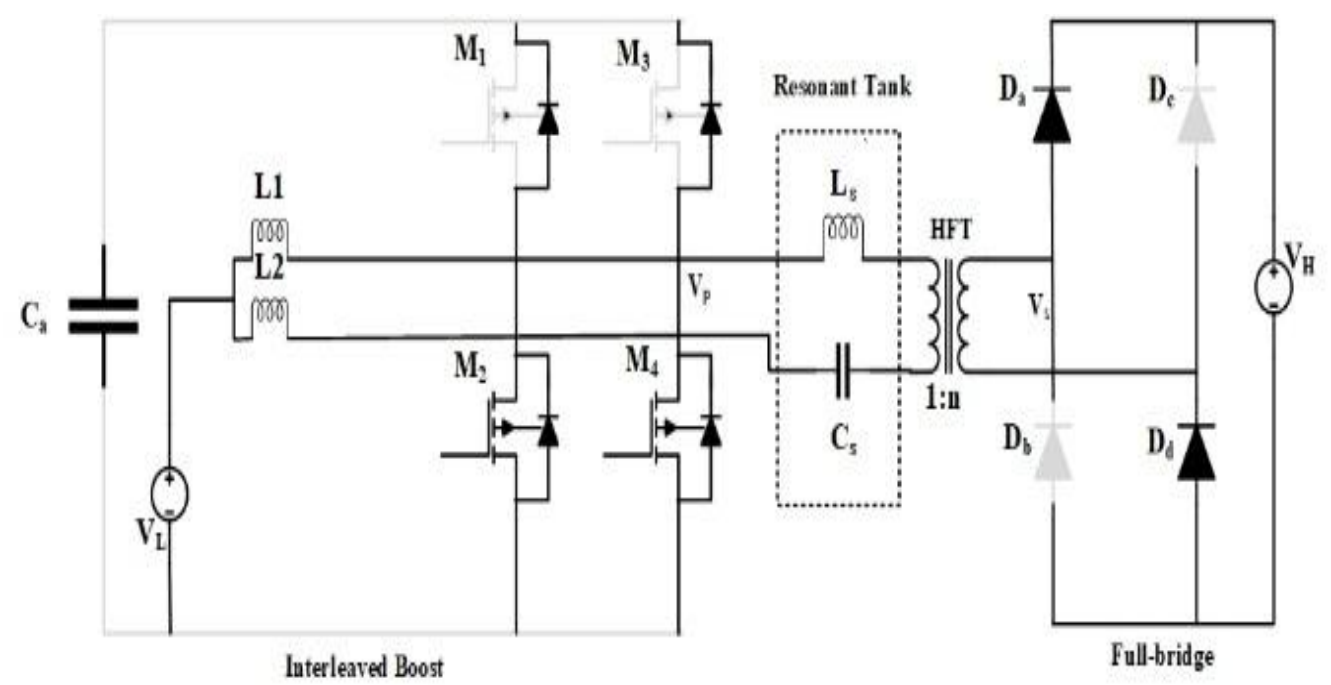

(b)

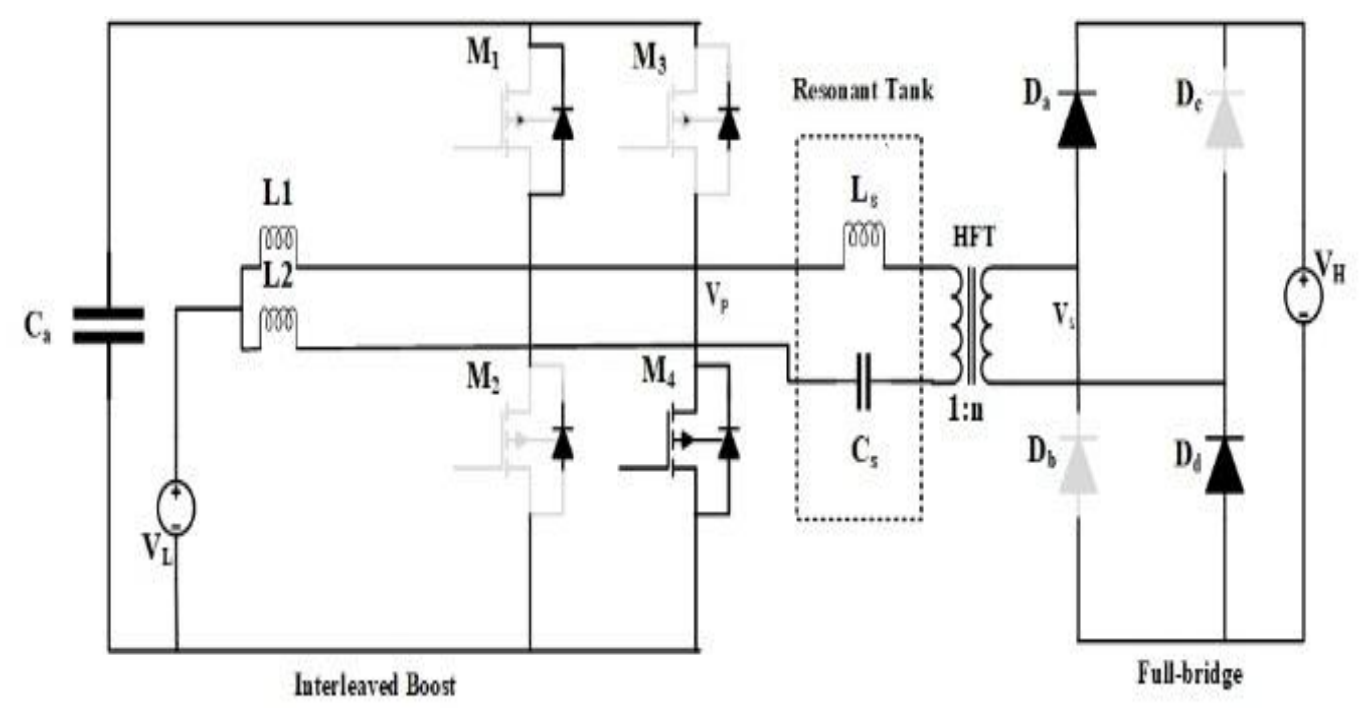

(c) 


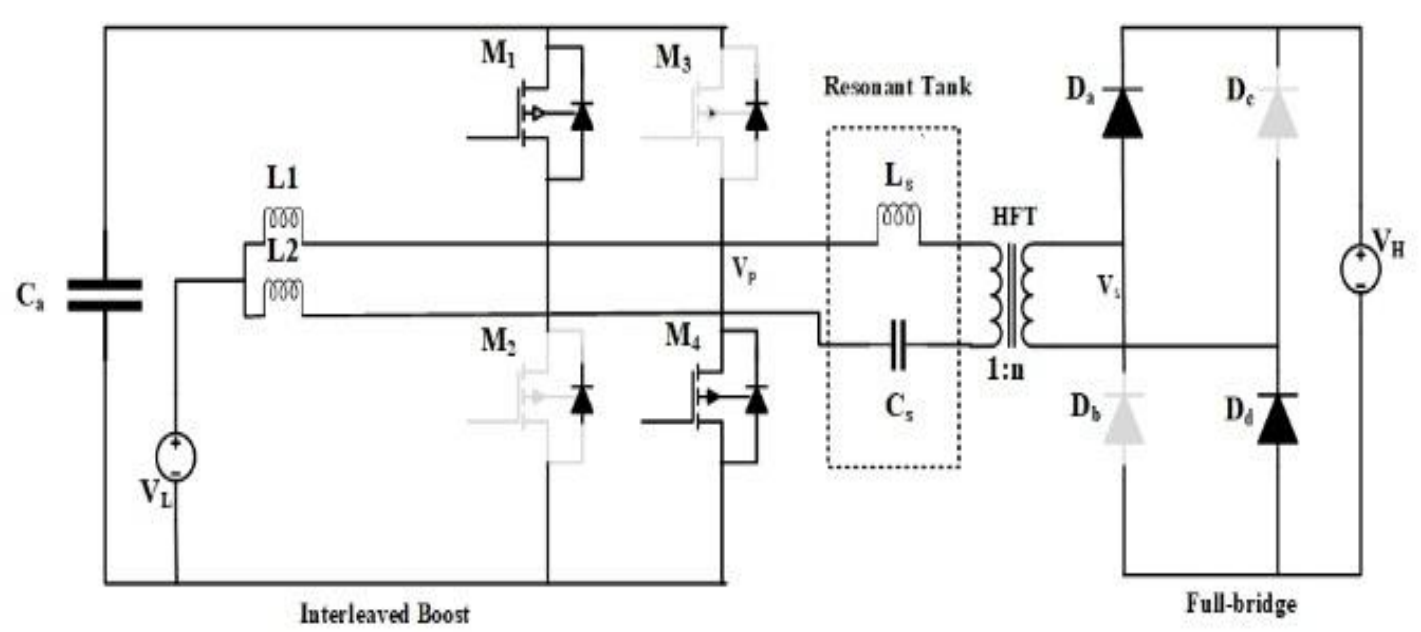

(d)

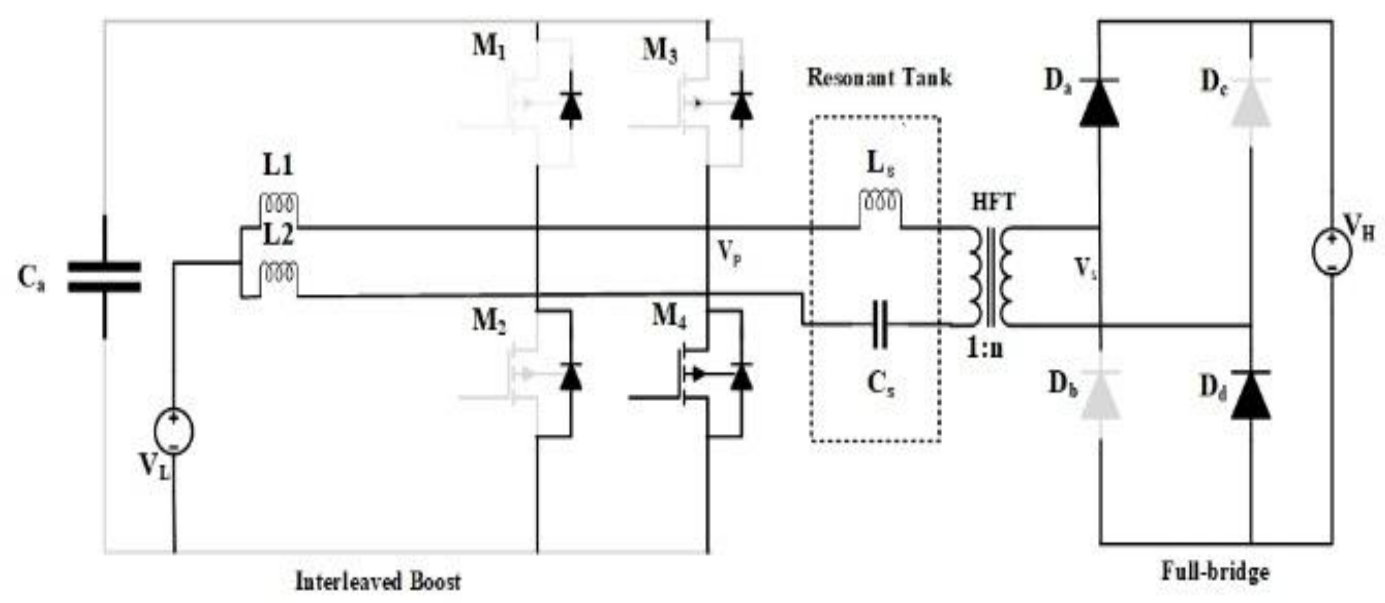

(e)

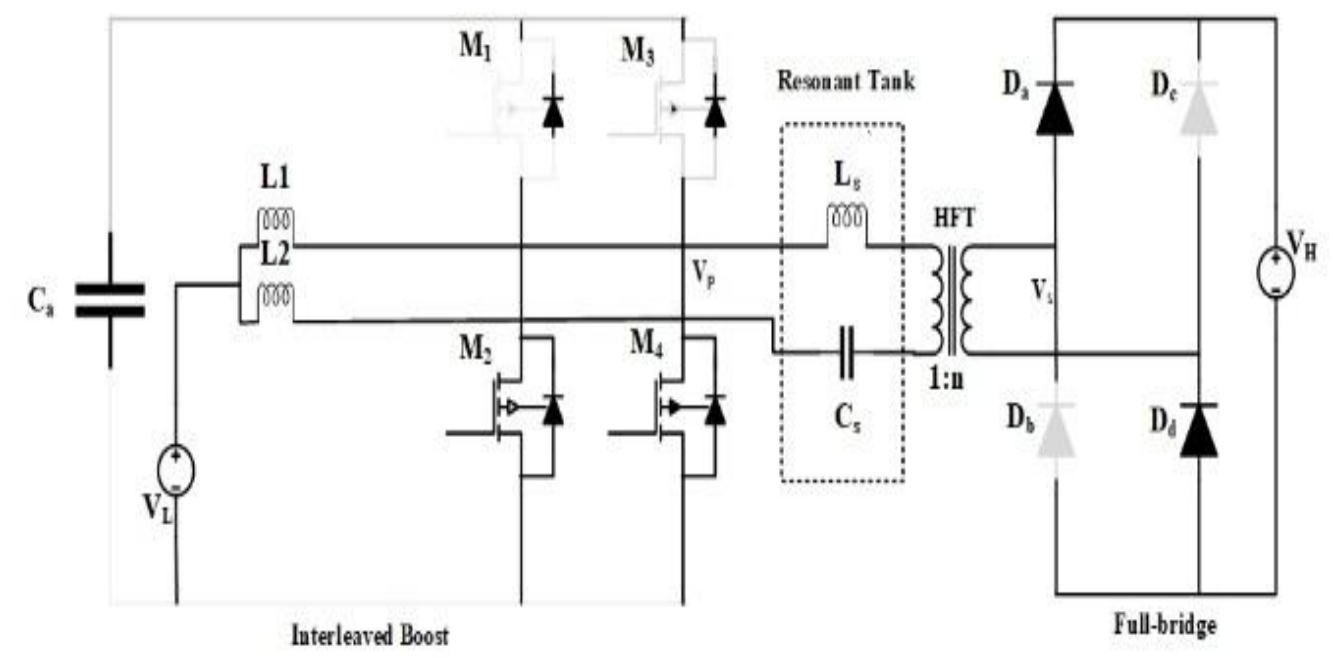

(f)

Fig.3. Proposed converter for different Switching modes

During the mode first as well as second, $\mathrm{V}_{\mathrm{p}}=0$ and $\mathrm{V}_{\mathrm{s}}=\mathrm{V}_{\mathrm{H}}$.

$$
\frac{d i_{L}}{d t}=\frac{V_{H}}{L_{m}}
$$


When both $\mathrm{M}_{2}$ and $\mathrm{M}_{4}$ are $\mathrm{ON}$, the current of inductor $\mathrm{L}_{1}$ and $\mathrm{L}_{2}$ are changed by $\mathrm{V}_{\mathrm{L}}$.

$$
\frac{d i_{L 1}}{d t}=\frac{d i_{L 2}}{d t}=\frac{V_{L}}{L}
$$

Here $\mathrm{L}_{1}$ and $\mathrm{L}_{2}=\mathrm{L}$. in addition, $\mathrm{L}_{\mathrm{s}}$ and $\mathrm{C}_{\mathrm{s}}$ and in the resonant tank stores energy is served to the HV side. The subsequent equation is obtained.

$$
\begin{gathered}
C_{S} \frac{d v_{C r}(t)}{d t}=i_{L S}(t) \\
L_{S} \frac{d i_{L s}}{d t}+V_{c S}(t)=-\frac{V_{H}}{n}
\end{gathered}
$$

The current of Ls and voltage on Cs at $t 0$ and V0, respectively, the solutions if $i_{L s}(t)$ and $V_{c s}(t)$ can be stated as follows:

$$
\begin{gathered}
i_{L s}(t)=I_{0} \cos w_{s}(t)-\frac{\left(n V_{0}+V_{H}\right)}{n Z_{r}} \sin w_{s}(t) \\
\begin{aligned}
V_{c S}(t)= & -\frac{V_{H}}{n}+I_{o} Z_{s} \sin W_{s}(t) \\
& +\left(V_{0}+V_{H} / n\right) \cos w_{r} t
\end{aligned}
\end{gathered}
$$

Mode III [ $\mathrm{t}_{2}-\mathrm{t}_{3}$ ] [Fig. 4 (c)]: On $\mathrm{t}_{2}$ the devise $\mathrm{M}_{2}$ is turned-off and the body diode of $\mathrm{M}_{1}$ commences to behavior since of the positive current of $i_{L 1}$. The voltage $V_{p}$ commutes to $V_{a}$, temporarily the inductor $L_{1}$ is discharged and $\mathrm{i}_{\mathrm{L} 1}$, reductions:

$$
\frac{d i_{L 1}}{d t}=\frac{V_{L}-V_{a}}{L}
$$

Mode IV $\left[\mathrm{t}_{3}-\mathrm{t}_{4}\right.$ ] [Fig. 4 (d)]: $\mathrm{M}_{1}$ opens. The voltage is zero at $\mathrm{t}_{3}$. The end of this phase, until $\mathrm{M}_{1}$ is closed at $\mathrm{t}_{4}$

Mode V [ $\mathrm{t}_{4}-\mathrm{t}_{5}$ ] [Fig. 4 (e)]: At $\mathrm{t}_{4}, \mathrm{M}_{1}$ is closed. Due to the positive current of $\mathrm{i}_{\mathrm{Ls}}$, the body diode of $\mathrm{M}_{2}$ twitches to comportment. Therefore, the voltage $\mathrm{V}_{\mathrm{p}}$ transitions to 0 , and the inductor $\mathrm{L}_{1}$ starts to be charged by $\mathrm{V}_{\mathrm{L}}$ yet again.

Mode VI [ $\left.\mathrm{t}_{5}-\mathrm{t}_{6}\right]$ [Fig. 4 (f)]: at $\mathrm{t}_{5}, \mathrm{M}_{1}$ is turned ON with zero voltage.

After $t_{6}$ a same process the whole thing in the next cycle of the switching period.

\section{Convertor Design}

A $1000 \mathrm{~W}$ converter design to operate at $110 \mathrm{kHz}$ switching frequency is taken to identify the main parameter design. The parameters are follow $\mathrm{V}_{\mathrm{L}}=100 \mathrm{~V}-180 \mathrm{~V}, \mathrm{~V}_{\mathrm{H}}=250 \mathrm{~V}$ resonant frequency $f_{\mathrm{r}}=90 \mathrm{kHz}$.

\section{A. Turns Ratio of the Transformer}

The turn's proportion of the transformer would be intended to mark indisputable that the power and voltage can be controlled with in the complete range of low to high voltage. This can be identified effortlessly since the regularized the voltage improvement of the converter can be widely controlled. In the case of a larger duty cycle $\mathrm{D}$, a lower voltage strain can be obtained on the primary side switch. With the new point of view for the resonant period, the main duty cycle of the resonant energy stored in the resonant tank is not affected by the smallest value of $\mathrm{D}$ and 1-D. with respect to increase the capacity of resonant tank circuit, the duty cycle should be taken 0.45 . Taking these factors into account, it is suggested to select the transformer's turn's ratio. When setting duty cycle is 0.45 the voltage at center of the complete voltage range [7].

Established on these consideration, the turns ratio of the transformer is calculated at $n=1$ so that duty cycle $\mathrm{D}=0.5$ after the battery voltage is at center $140 \mathrm{~V}$.

\section{B. Resonant Tank}

The main concern for the specification of the resonant tank (that is, $\mathrm{L}_{\mathrm{r}}$ and $\mathrm{C}_{\mathrm{r}}$ ) is to make the resonant frequency equivalent to the SF of the converter. In edict to decrease the current stress and conduction loss linked to circulating current, the worth of the resonance tank must be larger. But, the peak voltage on the resonant capacitor is equivalent to the impedance $Z_{r}$. However, a larger resonant inductance will damage the capacity and power thickness of the converter. The value of $Z_{r}$ is recommended to be in the range of 15 to 30 . 
For the scheme example, seeing that the actual worth of $\mathrm{C}_{\mathrm{r}}$ is $50 \mathrm{nf}$, select $\mathrm{C}_{\mathrm{r}}$. Then, given the resonant frequency, the resonant inductor $\mathrm{L}_{\mathrm{r}}$ is $44.54 \mathrm{uH}$.

\section{Filter Inductors L1 and L2}

The Boost converter on the primary side function in the interleaved method. For the assumed duty cycle $\mathrm{L}_{1}=\mathrm{L}_{2}=\mathrm{L}$, the current ripple and the total current wave $\Delta \mathrm{I}_{\mathrm{L}}$ on the battery side can be designed as:

$\Delta I_{L}=\frac{V_{L}(1-D) T_{S}}{L}$

Considering the current ripple and the soft switching performance of the primary side switch, $\mathrm{L}_{1}$ and $\mathrm{L}_{2}$ are designed to be $250 \mathrm{uH}$.

\section{Clamping Capacitor Ca}

$\mathrm{Ca}$ is designed based on the wave on the capacitor, which is the similar as the scheme of filter capacitors in maximum power converters. In a scheme example, a $10 \mathrm{uF}$ capacitor is used for $\mathrm{Ca}$

\section{Simulation Results}

The Isolated Soft Switching Current Fed Series LC Resonant DC-DC Converter is simulated by using MATLAB SIMULINK to authenticate the theoretic notions of DC-DC convertor.

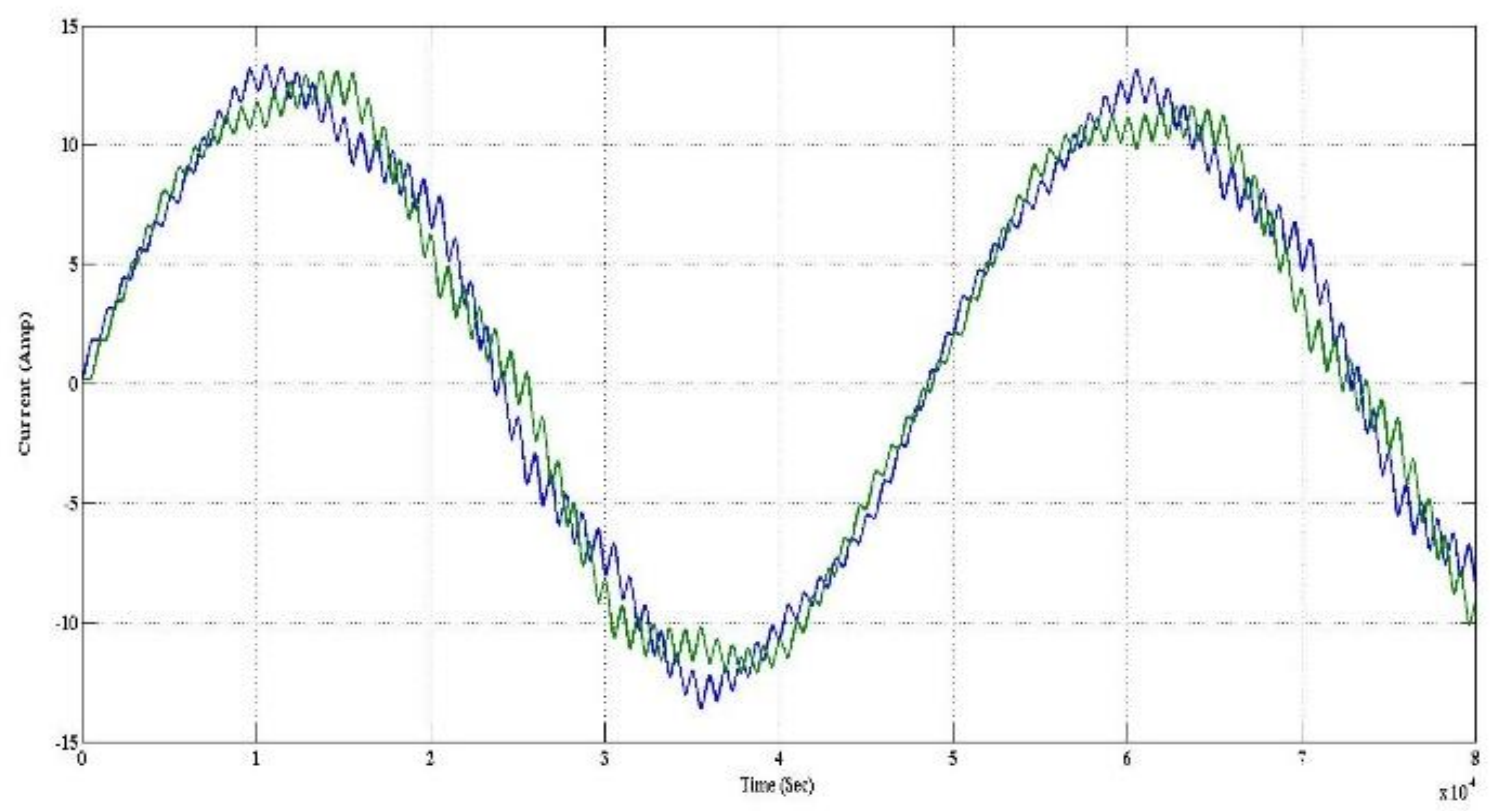

Fig.4 Waveform of the primary side boost converter

In Fig.4 shows an input side interleaved inductor current waveforms. It is vibrant that the simulated waveforms contest with the theoretic examination.

In Fig. 5 displays that zero voltage switching at key switches $M_{1}$ to $M_{4}$. Where it is seen soft switching attained for all switches. 


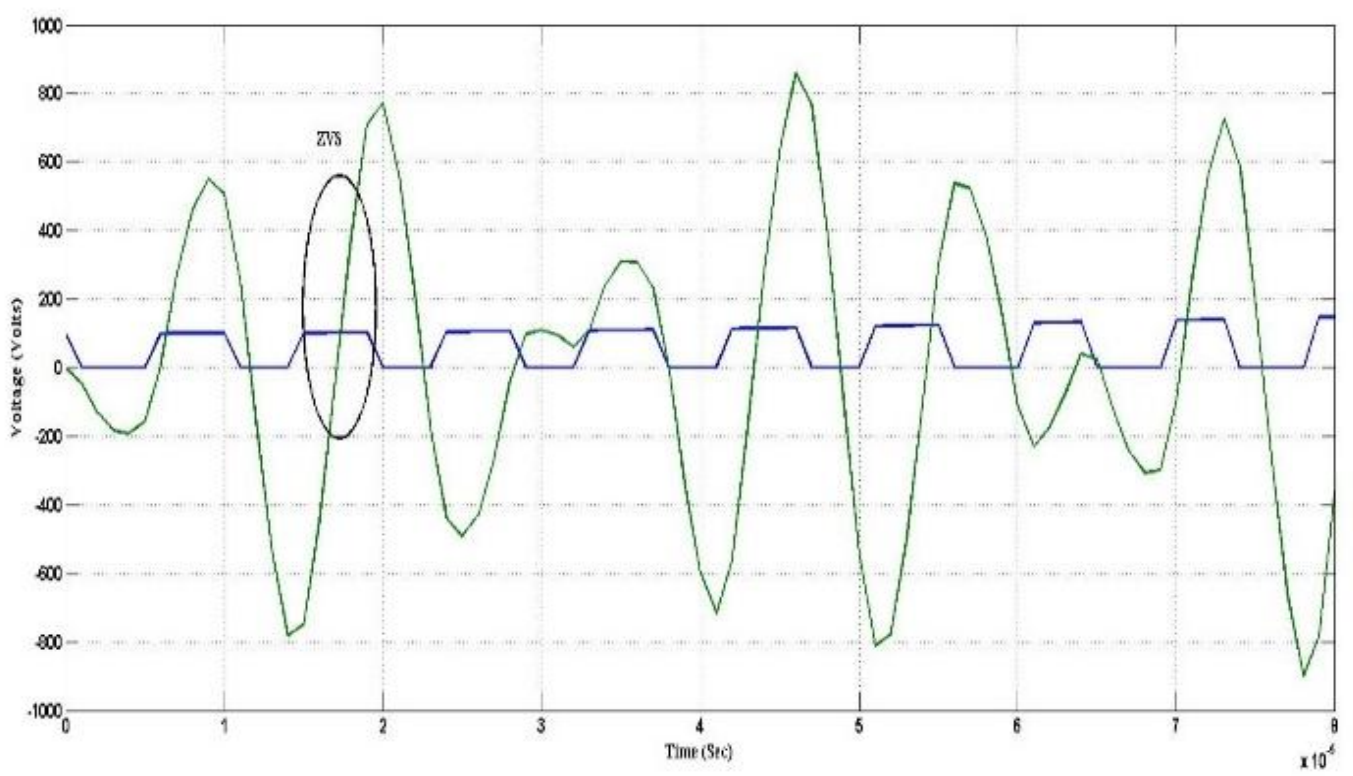

Fig.5 Zero voltage switching waveforms primary side switches in the advancing mode

The waveform of the resonant tank voltage at primary cross of the transformer presented in fig. $6100 \mathrm{~V}$ input voltage achieved at primary cross of the high HFT. Where it is seen simulated waveform counterpart with the theoretical analysis.

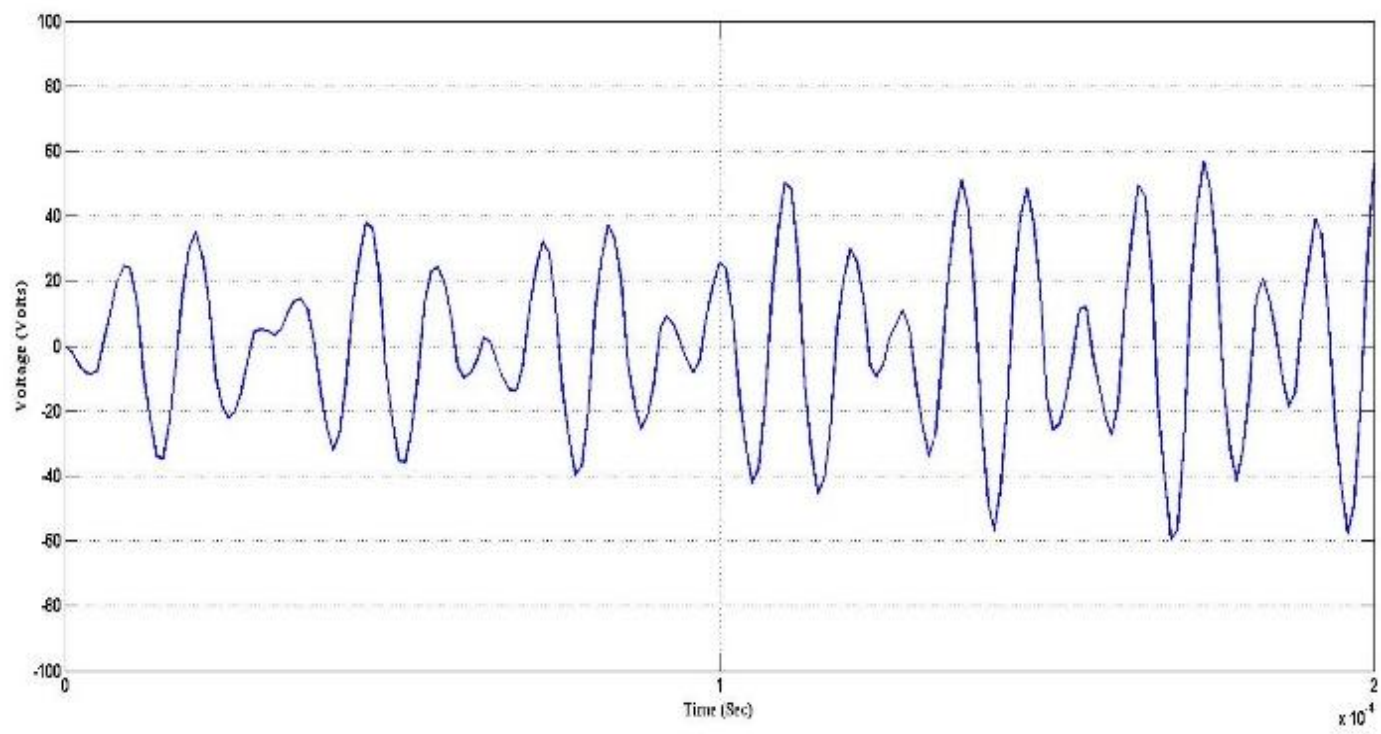

Fig.6 Waveform of the resonant tank in forward mode.

\section{Conclusion}

Isolated Current Fed Series LC Resonant DC-DC Converter takes occurred offered and substantiated in this article. Theoretic examination of simulated confirmation specifies that zero voltage switching achieved for primary side of semiconductor switches and conduction losses in minimized and efficiency of the converter improvised. The investigation and simulated verification designate that offered convertor is suitable for electrical vehicle charging. It can be used in maintainable energy power system uninterruptable power supplies, micro grids etc.

\section{References}

A. Chub, D. Vinnikov, F. Blaabjerg, and F. Z. Peng, "A review of galvanically isolated impedance-source dc-dc converters,” IEEE Trans. Power Electron., vol. 31, no. 4, pp. 2808-2828, Apr. 2016 
X. Pan, H. Li, Y. Liu, T. Zhao, C. Ju, and A. K. Rathore, "An overview and comprehensive comparative evaluation of current-fed isolated-bidirectional dc/dc converter," IEEE Trans. Power Electron.vol. 35, no. 3, pp. 2737-2763, Mar. 2020..

P. Biczel, "Power electronic converters in DC microgrid," in Proc. Compat. Power Electron. 2007, pp. 1-6..

A. K. Rathore, A. K. S. Bhat, R. Oruganti, "A comparison of soft-switched DC-DC converters for fuel-cell to utility-interface application", Proc. IEEE Power Convers. Conf., pp. 588-594, 2007

V. Yakushev, V. Meleshin, and S. Fraidlin, "Full-bridge isolated current fed converter with active clamp," in Proc. 14th IEEE Appl. Power Electron. Conf. Expo., 1999, pp. 560-566.

S. Jalbrzykowski and T. Citko, "Current-fed resonant full-bridge boost DC/AC/DC converter," IEEE Trans. Ind. Electron., vol. 55, no. 3, pp. 1198-1205, Mar. 2008

S.N. Manias, and G. Kostakis, "Modular DC-DC convertor for high-output voltage applications," In Proc. IEEE B-Electric Power Applications, vol.-140, No. 2, pp. 97-102, 1993.

H.L. Chan, K.W.E Cheng, and D. Sutanto, "Phase-shift controlled DC-DC convertor with bi-directional power flow," In Proc. IEEE Proceedings-Electric Power Applications, vol-148 No.2, pp.193-201, 2001

R. Rabinovici, and B.Z. Kaplan, "Novel DC-DC convertor schemes obtained through duality principle and topological considerations," In Proc. Electronics Letters, vol- 27 No. 21, pp.1948-1950, 1991.

H. Tao, A. Kotsopoulos, J.L Duarte, and M.A Hendrix, "Family of multiport bidirectional DC-DC converters," In Proc. IEE Proceedings-Electric Power Applications, vol-153 No.3, pp.451-458, 2006.

M.B Camara, H. Gualous, F. Gustin, and A. Berthon, "Design and new control of DC/DC converters to share energy between supercapacitors and batteries in hybrid vehicles," In Proc. IEEE Transactions on Vehicular Technology, Vol-57 No.5, pp.2721-2735, 2008 